\title{
Entrevista a la Dra Ana Bloj, Titular de la Cátedra Intervenciones en Niñez y Adolescencia de la Facultad de Psicología
}

Como planteábamos en la Nota Editorial con esta entrevista abrimos una nueva sección en la Revista Barquitos Pintados en donde invitamos a participar a cátedras de la carrera de Psicología.

Una primera línea de trabajo que nos proponemos es la de reconstruir el recorrido de las cátedras, historizar las propuestas curriculares y el lugar en el que se ubican respecto de la formación del-a psicólogo-a. ¿Cómo piensan la formación y cómo se piensan en ese proceso?

En este sentido es que le pedimos a Ana Bloj que nos transmita su lectura del proceso de lo que hoy es la Cátedra de Intervenciones en Niñez y Adolescencia a partir de la apertura democrática.

Esta breve introducción oficia de disparador para ubicar algunos interrogantes respecto del lugar de la niñez en la formación de los psicólogos-as e invitar a la reflexión

B:P: El psicoanálisis que retorna a la universidad con la recuperación democrática en 1983, luego de su expulsión en la dictadura cívico-militar, se va convirtiendo en hegemónico y ciertas palabras aparecen casi como prohibidas: desarrollo, evolución, diagnóstico, juego. Melanie Klein, más aún autores como Arminda Aberastury, quedan prácticamente fuera de la currícula.

En entrevistas con psicólogos-as que cursaron la carrera de Psicología durante los años 80 y 90 se plantea claramente la borradura de clínica en niños-as. El abordaje de la clínica en niñez se da en seminarios optativos o extracurriculares que supuestamente cubrirían áreas de vacancia en la formación del Psicólogo.

Los espacios curriculares en donde se rescata la posibilidad de pensar en la figura del-a niño-a están referidos a las materias educativas: "las educativas". Una de las entrevistadas las ubica como materias "depósito", ya que no eran consideradas desde el discurso hegemónico en la facultad como materias de "formación”. Es más, algunos entrevistados consideraron que las educativas les abrían panoramas (más allá de la práctica de Psicología Educativa) para pensar el lugar de la cultura en la constitución subjetiva, para pensar la relación de la constitución subjetiva y las instituciones.

(Grande, 2015) ¿Cómo fue tu experiencia de formación en la Carrera de Psicología en la apertura democrática?

A.B: El nuevo plan de estudios post dictadura del 76 llegó con aires de optimismo. Alegría, un deseo imparable y contenido luego de tantos años de represión, oscuridad y silencio.

Comencé mis estudios prácticamente con el advenimiento de la democracia, y recuerdo que 
se daba un fenómeno que podría llamar "furor Lacan": todos querían enseñarnos Lacan. El problema es que se trataba de un Lacan desgajado de historia, un Lacan que se anticipó a las lecturas freudianas. Era el Lacan que nuestros docentes habían estudiado en grupos de estudio, cerrados, aislados... eso tuvo su efecto en la transmisión. Un Lacan antes que Freud y otros antecesores. Un Lacan para la práctica privada, liberal en consultorio y con adultos.

En este contexto, el trabajo con niños, el trabajo con grupos, en instituciones y la práctica psi como práctica social eran, de algún modo y especialmente en los primeros años francamente rechazada.

Esto me llevó, en lo personal, a dudar incluso sobre la elección de mi carrera. Había comenzado con la convicción de que lo que quería era trabajar con niños-as y en espacios sociales y no encontraba nada o muy poco que fuera por allí.

La primera mención a una práctica posible en infancia vino de la mano de las materias pedagógicas, para quienes cursábamos el profesorado. El cursado se iniciaba en el tercer año, junto con la materia Trabajo de Campo Educativa.

Allí comenzamos a escuchar una lectura diferente acerca de las posibilidades de ejercer una práctica en instituciones -educativas- se abría la posibilidad de trabajar con niños. La interdisciplina comenzaba a transmitirse como un objetivo posible en una práctica con otros, y la transmisión de textos como Althusser, Marx y Freire venían por fin a "abrirnos la cabeza" y sacarnos de aquel marco de formación en la que primaban los discursos que solo permitían pensar en una práctica en consultorio privado de tipo liberal.

Una de las materias era dictada por Ovide Menin, que venía del exilio, y que venía con una vitalidad y deseo de formar muy movilizantes.

Recuerdo que una de las materias que dictaba era Tecnología Educativa. La primera clase llegó al aula, y sin presentarse nos empezó a pedir que cambiásemos los bancos de lugar, nos puso en movimiento, nos hizo acercar al pizarrón, nos pidió que juntásemos todas las mesas, armando una mesa grande, y nos invitó a sentarnos alrededor. Cuando estuvimos sentados nos dijo: "esto que acabamos de hacer es tecnología educativa". Y así arrancó. Ovide tenía una fuerte formación en Psicología Genética, y primaba la idea de que se aprendía a través de la acción. Estábamos en las antípodas de la formación psicoanalítica que veníamos teniendo.

En estas materias - "las pedagógicas" y "las educativas"- no teníamos que repetir los clishés psicoanalíticos. Se nos invitaba a pensar en un sentido crítico y se nos transmitía alguna dimensión de la historia de nuestra práctica y de la práctica educativa en general.

El psicoanálisis no quedaba por fuera de nuestras lecturas, pero adquiría un lugar sin idealización. Era transmitido como una corriente teórica, y no como verdad ni como religión, sino como un marco teórico que podíamos elegir para sostener nuestra práctica. En esa primera cohorte de la democracia de la que formé parte, la infancia no se transmitía ni siquiera en las materias biológicas, desde la perspectiva del desarrollo. 


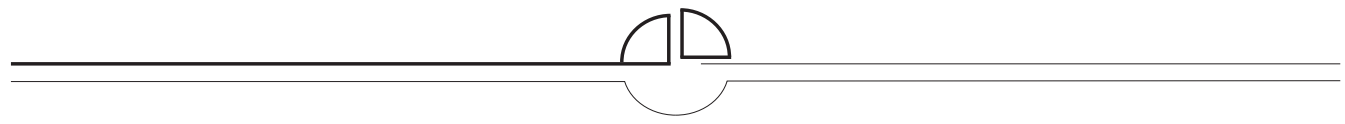

No obstante, el plan del 83 tenía una virtud que permitió que alguna transmisión sobre la figura del-a niño-a fuera posible: se trató del único plan en el país que incluía 4 cátedras que versaban sobre la psicología educacional.

Nuestra cátedra Psicología Educativa II, cuyo titular era Ovide Menin, se ubicaba en el Gto año de la carrera, con lo que los estudiantes llegaban con alguna formación de Trabajo de Campo Educativa (ubicada en el tercer año del ciclo básico) y de Psicología Educativa I en el segundo. Paralelamente a nuestra materia, los estudiantes cursaban la Residencia Educativa. En aquel momento los docentes eran: Cecilia Bixio, Ángela Sánchez, Gabriela Abecasis, Annelie Barea y Norberto Boggino. Con los años ese esquema se fue modificando, hasta el concurso del año 92, en el que se modificó mucho el equipo de cátedra.

\section{B.P: ¿Cómo era la relación en cuanto a contenidos-objetivos con las otras asignaturas educativas del plan de estudios?}

A:B: Con Trabajo de Campo Educativa se realizaba un primer acercamiento de los estudiantes al campo de la educación. "un área de actividades eminentemente operativas en contacto directo con la realidad." (1era resolución Plan de estudios) Los 2 ejes principales del programa abarcan un encuadre teórico centrado en el análisis del campo de la educación y los denominados nuevos escenarios educativos; y una introducción a la investigación en el campo, cuestión que debería ser retomada en las cátedras metodológicas (I y II) subsiguientes.

En el ciclo superior, 5to y 6to año se desarrollaban 3 cátedras del campo educacional. El ciclo superior aludía a "profundizar el marco teórico brindado en el ciclo anterior (Básico) y articularlo con las prácticas profesionales, así como proporcionar formación en metodología de la investigación en el campo psicológico".

En el 5to año los alumnos cursaban la cátedra Psicología Educativa I.

Los contenidos mínimos estaban centrados en: El proceso de aprendizaje y las condiciones que lo posibilitan. Los trastornos de los sujetos del aprendizaje. La práctica educativa. La función del psicólogo en el campo de la educación. Modalidades de abordaje.

El hilo conductor de los contenidos mínimos de las 4 cátedras se hilvanaba alrededor de 4 ejes:

- La investigación

- La interdisciplina

- El análisis del campo de la educación desde una perspectiva histórica

- Las intervenciones del Psicólogo Educacional.

Las cuatro asignaturas se encontraban vinculadas explícitamente con una de las incumbencias laborales que -expresadas bajo el rubro "alcances del Titulo"- se reducen a "diagnosticar, asistir, orientar y asesorar en todo lo concerniente a los aspectos psicológicos del quehacer educativo, la estructura y la dinámica de las instituciones educativas y el medio social en que éste se desarrolla”. 


\section{B.P: ¿Qué dificultades se les presentaban como cátedra en esos momentos?}

A:B: El gran problema que teníamos era la formación con la que llegaban los estudiantes: en su mayoría, y a pesar de haber cursado las materias que acabo de mencionar, ellos nos decían que no les interesaba la educación, que querían trabajar en consultorio privado. Ovide Menin, en la clase inaugural de cada año parodiaba y les preguntaba: ¿Ya compraron el diván y el gomero para el consultorio? ¿Están seguros de que todos ustedes van a poder trabajar allí? ¿Y si no consiguen tantos pacientes? Vayan pensando... les decía... Y luego, para incomodarlos, ponerlos en acción les decía, seguramente habrán visto crecimiento y desarrollo del niño en tal materia del ciclo básico, ¿no? Porque en esta materia vamos a dar por sabidos esos temas. Veíamos las caras de los estudiantes estupefactos, decían que no, que no habían visto nada más que Freud y Lacan, y para trabajar en consultorio privado, y con adultos.

Y ahí, como decía Ovide, empezábamos a "arremangarnos".

Si bien en las anteriores educativas se daba algo de psicología infantil, por decirlo de algún modo, el eje de nuestra materia estaba en el diagnóstico e intervención en el campo de la educación (que en aquel momento se llamaba educación formal y no formal, lo cual incluía muchísimos espacios culturales que transitaban niños-as y adolescentes) con lo que teníamos que disponernos a dar aquello que estaba contemplado para las materias de psicoanálisis del ciclo básico, ya que la cátedra que debía dictar esos temas según lo establecido en el plan de estudios no lo hacía.

Aquí cabe una importante aclaración: el plan de estudios incluía esos desarrollos: infancia, adolescencia, etapas, etc. El problema se suscitaba en su implementación. Luego de concursar los profesores se negaban a dar esos temas con diferentes argumentos: que el "verdadero" psicoanálisis no se ocupaba de los niños, que eso era "psicología del yo" y no se trabajaba sobre la dimensión de lo inconsciente, que Melanie Klein había sido una delirante y algunos otros argumentos.

\section{B.P: ¿Cómo caracterizarías la cátedra Psicología Educativa II? En cuanto a su organización, los contenidos, los autores que se trabajaban}

A:B: La cátedra tenía unas cuantas virtudes: una de ellas era que era en sí misma una cátedra interdisciplinaria. Estaba integrada no solo por psicólogos, sino también por médicos, algún psiquiatra que venía a hacer adscripciones, y pasantes del campo de la educación, con lo que los debates se enriquecían mucho. Insistíamos fuertemente en los abordajes interdisciplinarios, cuestión que subsiste hasta la actualidad.

Entonces, decía, tomábamos el relevo de la vacancia que la carrera dejaba, y el eje fundamental de nuestros desarrollos era el diagnóstico de niños y adolescentes en edad escolar.

Si bien éramos una cátedra de psicología educativa, trabajábamos mucho los aspectos clínicos de la niñez, trayendo a colación autores que habían quedado en el olvido, como 
Melanie Klein, Arminda Aberastury, Bowlby, Spitz, Wallon, Ana Freud. Y también autores en ese momento más actuales, franceses, que tampoco eran mencionados en la facultad: Maud y Octave Mannoni y Francoise Dolto. Teníamos un profesor titular totalmente abierto y respetuoso de los referentes teóricos que cada uno de nosotros pudiera tener. Es más, los alimentaba.

A ello le agregábamos la transmisión de la Psicología Genética para abordar los mal llamados "problemas de aprendizaje". Lográbamos una interesante articulación de la psicología genética con el psicoanálisis.

Nos ocupábamos de trabajar las entrevistas diagnósticas, la primera hora del juego con el psicoanalista, la entrevista con padres, las entrevistas con los docentes, y hasta los modos en los que redactar informes para padres, escuela, juzgados, etc.

Trabajábamos tanto los abordajes singulares, de consultorio, como institucionales y comunitarios. Para ello incluíamos material de Stolkiner, Elichiry; Luzuriaga, Renau. En fin, clásicos y autores del momento. Siempre incluíamos autores europeos, americanos y nacionales. La perspectiva era muy amplia y siempre pensada en función de la práctica concreta.

Los programas variaban año a año. Encontré un programa de 1990 en el que veíamos desde el recién nacido hasta la adolescencia, en el que no solo tenía lugar la dimensión del inconsciente infantil sino también los aspectos del yo, cuestión muy repudiada en aquel momento. La cuestión evolutiva era profundamente cuestionada, a punto tal que solo se hablaba de los momentos lógicos del psiquismo, sin poner en tensión cierta cronología indispensable del crecimiento para un abordaje clínico en cualquier campo.

Todo esto era transmitido en clave de teoría pensada para una práctica inminente.

Teníamos a favor de que los estudiantes empezaban a movilizarse, casi diría, a angustiarse, porque comenzaban a transitar sus prácticas y en el segundo cuatrimestre reconocían que lo que les dábamos les resultaba un insumo para su práctica.

La preocupación que permanentemente escuchábamos en los encuentros de los docentes que trabajamos en el área educacional era (y es) la dificultad por transmitir la articulación entre las teorizaciones propias de la psicología educacional y la práctica efectiva. Los alumnos suelen decirnos que, una vez graduados, se encuentran con una concreta carencia para posicionarse y dar respuestas en una práctica efectiva.

En varios de los encuentros con otras cátedras de Psicología Educacional del país y en las Jornadas de Investigación organizadas por la Facultad de Psicología de la UBA, los docentes repetían esta dificultad. Se trata por tanto de un problema compartido. En otras facultades nos decían que nos envidiaban, porque la mayoría de los planes de estudio incluía una sola cátedra de psicología educacional.

\section{B:P: ¿Cómo creés que inciden estas dificultades en el modo de trabajo de la cátedra?}

A.B: Desde la cátedra, ésta ha sido una inquietud constante. Hemos intentado construir 
respuestas, no solo aquellas ligadas los contenidos transmitidos sino también a los modos específicos de transmisión y evaluación. Se trata de intentar interpelar los desarrollos teóricos sobre la base de temáticas y problemáticas que se configuran en el campo, sin cristalizarlas, aislarlas o coagularlas. En un intento de vivificar la teoría, apostamos a promover interrogantes y favorecer el debate conceptual con la meta de aportar elementos que aludan a resignificar nuestras propias representaciones, prejuicios. Tratamos de abordar las prácticas psicoeducativas y sociales en términos de favorecer la subjetivación y la aparición participativa de los sujetos para su crecimiento social.

Plantear la existencia de teorías que puedan ser analizadas fuera de sus prácticas supone un retroceso analítico. Las prácticas psicológicas en el ámbito educativo se han planteado en términos individuales sin considerar las problemáticas en los conjuntos sociales.

Un elemento que ha colaborado fuertemente a los desarrollos y los modos de transmisión ha sido la veta pedagógica con la que pensamos cada año los programas.

\section{B.P: ¿La veta pedagógica? ¿Cómo sería?}

A.B: No se trata de la vertiente de la pedagogía tradicional, sino de una pedagogía activa y dinámica, en permanente transformación. Esta mirada nos ha permitido resignificar tanto los programas como la evaluación y las dinámicas de trabajo. Todas ellas como respuesta activa a las diferentes dificultades con las que nos fuimos encontrando a lo largo de los años.

Siempre tenemos presente la importancia de poner en tensión teoría - práctica, y a través de diversos dispositivos y dinámicas de trabajo alimentamos esos aspectos: jornadas de debate documental, colegas que vienen a presentarnos sus experiencias, intercambios con otras cátedras de facultades afines, práctica docente sostenida en el trabajo centrado en la tarea de Pichon Rivière, talleres, roll playing, escritura de ensayos y un permanente repensar los modos de evaluación hacen que nuestro programa y modos de abordajes se vean modificados años a año. Nosotros decimos que se trata de "hacer la cátedra", y de algún modo sostenemos aquellos preceptos del aprendizaje a través de la acción piagetianos, junto con referentes de la teoría psicoanalítica.

En esto, año tras año nos acompañan un grupo de entre 20 y 30 adscriptos y ayudantes alumnos. Este aspecto colabora con la dinámica de la cátedra y su movilidad, trabajando en la transmisión y preparación de las jóvenes generaciones de colegas.

\section{B:P: Esta "veta pedagógica" ¿interroga las modalidades de la formación, la posibilidad de la transmisión?}

A.B: El riesgo actual de la transmisión académica es el de convertir a los conceptos en barreras defensivas de los futuros profesionales, impidiendo un acercamiento genuino a la realidad. El concepto, la teoría, se convierte en una pantalla, disfraz que en lugar de acercar 
al profesional a la práctica lo distancia, lo deja muchas veces impotente. Como verán, esta es una de nuestras principales preocupaciones.

Los talleres, el laboratorio, apuntan a que los alumnos "amasen" el material como arcilla y planteen nuevas producciones, siempre recuperando la historia y el bagaje personal.

El resultado más interesante es que muchos de los trabajos tienen el nivel necesario para ser publicados. De hecho, algunos de ellos fueron publicados en el libro-CD de la cátedra en el año 2007 y figuran online. El libro fue tomando forma de página de la cátedra en la medida en que se fue ampliando y dando lugar a aportes múltiples y actividades de docencia.

Muchos alumnos, cuando subimos aquellos trabajos, sintieron la propia necesidad de publicar sus producciones, en lo que interpreto como un trabajo de autoafirmación y valoración de lo producido. Es un tema que vamos a retomar seguramente.

Les traje una carta que habla de nuestro modo de trabajo. Esta carta la escribí en el momento en que propusimos que los parciales fueran análisis y abordaje de casos desde nuestra disciplina, en el que les pedíamos que construyan una hipótesis diagnóstica, una estrategia de intervención que considere lo colectivo o lo interdisciplinario de ser posible, desde una perspectiva crítica. Así como tuvimos enormes resistencias cuando les planteamos que realizaran un psicodiagnóstico del niño y otro del adolescente en edad escolar, hace muchísimos años, e instalamos el gran debate sobre psicodiagnóstico sí o psicodiagnóstico no; cuando propusimos esta forma de evaluación, tendiente a la puesta en tensión de los conceptos adquiridos, la negativa se tornó intensa. En ese momento decidimos tomar el parcial de todos modos, y antes de comenzarlo, los estudiantes recibían esta carta:

"La complejidad del sentido del verbo aprender provendría de la necesidad irreductible de afrontar y de comprender la complejidad y la diversidad de respuestas posibles a los enigmas de lo real."

\section{Charles Coutel}

Zambullirnos en las complejidades del mundo que habitamos y en los intersticios que se juegan entre el pasado, el vivir mejor en la actualidad y el desear un futuro utópicamente planteado es la dimensión en la que pensamos el aprendizaje y la transmisión en esta cátedra. La modalidad de evaluación que construimos apunta a considerar la evaluación como parte de un proceso que intenta acompañarlos y promover un análisis crítico de un campo particular: la educación, desde una disciplina particular: la psicología educacional. Pero esto es tan solo un paso en el camino. Necesitamos analizar y comprender para crear, construir, recrear, proponer diferentes formas de afrontar lo real. Creemos que cada uno de ustedes será capaz de posicionarse en esta dirección. Al menos es esto lo que deseamos promover. No buscamos una respuesta única, inmodificable. La propuesta es precisamente la opuesta: vislumbrar la multiplicidad de caminos, respuestas, con proyectos que pueden elaborarse a partir de una demanda por más recortada y específica que esta sea.

Evaluaremos por tanto la capacidad de análisis y la coherencia entre análisis-fundamentación 
y propuesta.

La disposición para relacionar y comprender los elementos de la realidad que se nos presenta, nos permitirá afrontar la multiplicidad de desafíos a los que nos convoca este principio de siglo en la articulación entre educación-sociedad-subjetividad.

Ana Bloj

Prof. Tit. Psicología Educativa II

\section{B:P: Esta carta tuvo el valor de una intervención. ¿Una transmisión en acto?}

A.B: Sí, hubo allí una apertura en lo que hace a pensar la importancia de la puesta en tensión teoría práctica. Fue fuerte para ellos recibir una carta del titular de la cátedra, en la que se explicitaban los sentidos de esa modalidad de evaluación.

Otra intervención fuerte la realizamos hará unos 8/9 años, cuando veíamos la apatía con la que venían los estudiantes al aula. Compartíamos esta preocupación con docentes del 6to año. Era un grupo particularmente indiferente. Los estudiantes entraban y salían del aula en cualquier momento, hablaban entre ellos, aun cuando invitábamos colegas o equipos a presentar experiencias, vaciaban el mate golpeándolo en la mesa mientras el profesor/a hablaba. Hasta que en un momento me dije: "estos chicos nos miran por tv"; todo esto es exactamente lo que todos hacemos cuando escuchamos televisión. Decidimos hacer una intervención. Los hicimos venir a todos en un horario, con carácter obligatorio, una de las adscriptas de aquello momento hizo el marco de una pantalla de Tv y desde allí les hablé, compartiendo las inquietudes que teníamos como docentes de la cátedra: les preguntábamos: ¿qué les pasaba? ¿Qué buscaban en el 6to año de la carrera, a punto de ser profesionales? Los invitamos a expresar, debatir y analizar dónde estaban parados y a qué se debía la apatía. Utilizaron diversos recursos: filmaciones, cámaras de fotos, revistas, imágenes, frases y unos “afiches catárticos”. Fue impresionante. Lo que más expresaron fue que estaban hartos del psicoanálisis dado de ese modo, de repetición de axiomas lacanianos. También se quejaban de cierto desgano que percibían en algunos docentes. Que querían escuchar otras teorías. Hablaron de sus expectativas al iniciar la carrera y de cómo se sentían en ese momento. Fue muy fuerte, pero lo más importante fue que logramos un efecto inmediato. Este trabajo se realizó a mitad de año, justo en el momento en que tenían que realizar el escrito de sus ensayos, y se dispararon a estudiar, leer y escribir de un modo increíble. Comenzaron a escuchar las clases y a participar activamente. ¡No lo podíamos creer!

\section{B:P: ¿Cómo llegaron a la cátedra de Intervenciones en niñez y adolescencia que tenemos desde el cambio de plan?}

A.B: Muy sintéticamente te diré que en el momento del surgimiento del cambio de plan lo 
que logramos fue de algún modo blanquear el modo y las temáticas con las que veníamos trabajando desde hacía décadas. Siempre nos hicimos cargo de la vacancia, del vacío que existía en la carrera respecto a las temáticas de la niñez y adolescencia. Siempre lo articulamos con el campo de la educación, de la salud y hasta en el jurídico, aunque pusiéramos más peso en el primero, pero la vacancia se daba en todos los campos.

Cuando la CONEAU vino a evaluarnos fuimos una de las cátedras mejor evaluadas, no nos realizaron señalamientos, todo lo contrario. Y una de las grandes críticas realizadas a la carrera fue que prácticamente no se veían contenidos de infancia, crítica acompañada de la exigencia de que así fuera. Esto fue considerado para nosotros una ocasión para visibilizar los que por tantos años veníamos haciendo, y allí planteamos convertirnos en la cátedra Intervenciones en Niñez y Adolescencia. Tanto el armado del programa, los contenidos mínimos y el nombre de la cátedra fueron pensados colectivamente. Fue un verdadero trabajo de equipo. Siempre nos planteamos la práctica docente desde la perspectiva de un "hacer la cátedra".

Necesito nombrar a sus integrantes: Cecilia Augsburger, Carlos Ruggeroni, Cristina Ronchese, Elida Penecino, Georgina Borzone, Ana Maschio, Analía Musumano, Mónica Castaño, María Crisalle, María Laura Crespín y Camila Vera. Todos ellos portan una muy buena formación académica, la mayoría con maestrías y doctorados aprobados o en curso.

\section{B:P: Si tuvieras que caracterizar, muy sintéticamente, cuáles son los núcleos conceptuales más potentes con los que trabajan en la cátedra, ¿cuáles, te parece, serían?}

A.B: Los objetos culturales y la producción de subjetividad. Un elemento que desde que ejercí como profesora titular siempre traté de incluir es el de los objetos culturales. Durante años trabajamos con el cine, otros con las artes plásticas, la música y luego la literatura. Ellos fueron elementos que colaboraron con el tejido de los diagnósticos, abordajes y propuestas de intervención. Esta arista fue planteada con más fuerza en proyectos de investigación y extensión, especialmente en los voluntariados universitarios. Lo concebimos como un elemento que participa fuertemente en la producción de subjetividad.

El modo de abordarlo no es solo teórico, sino que tratamos de que los estudiantes atraviesen esa experiencia cultural. Recuerdo que en algún momento abrimos un espacio en el que nos contábamos cuentos infantiles, para vivir o revivir esa primera experiencia vital. Sin experiencia, desde la perspectiva de Benjamin, la transmisión no adquiere la misma fuerza ni la misma posibilidad de apropiación.

Encontré este texto con el que comenzamos unos 6 años atrás un teórico inaugural y me gustaría compartirlo con ustedes: 


\section{EL HILO DE LA FÁBULA:}

"El hilo que la mano de Ariadna dejó en la mano de Teseo (en la otra estaba la espada) para que éste se ahondara en el laberinto y descubriera el centro, el hombre con la cabeza de toro, o, como quiere Dante, el toro con cabeza de hombre y diera muerte y pudiera ya ejecutada la proeza, destejer las redes de piedra y volver a ella, a su amor.

Las cosas ocurrieron así. Teseo no podía saber que del otro lado del laberinto estaba el otro laberinto, el del tiempo, y que en algún lugar prefijado estaba Medea.

El hilo se ha perdido también. Ahora ni siquiera sabemos si nos rodea un laberinto, un secreto cosmos, o un caos azaroso. Nuestro hermoso deber es imaginar que hay un laberinto y un hilo. Nunca daremos con el hilo; acaso lo encontramos y lo perdemos en un acto de fe, en una cadencia, en el sueño, en las palabras que llaman filosofía o en la mera y sencilla felicidad." (Borges, 1985, p: 481)

Y acto seguido esto les dije:

Las teorías muchas veces son esto: hilos, caminos o laberintos en los que perdernos, recibir o construir respuestas.

Ejercer esta profesión puede ser algo más que aplicar la teoría en la práctica:

Puede tratarse de ejecutar proezas,

Encontrar hilos de Ariadna,

Perderlos,

Extraviarnos y encontrarnos en caminos laberínticos o en universos caóticos.

También se trata de sueños, actos de fe, filosofía o excepcionales instantes de felicidad.

B:P: Muchas gracias, Ana. Creemos que, luego de esta experiencia que nos has transmitido, tenemos más claro las razones por las cuáles hemos inaugurado este espacio de la revista Barquitos Pintados, experiencia Rosario. Gracias de nuevo

\section{Referencias}

- Grande, S (2015) Prácticas de los psicólogos en la red de Salud Pública, sus obstáculos y referencias con la formación universitaria. El caso Rosario. Tesis de Maestría en salud Pública. CEI. Instituto Lazarte. Rosario, inédito

- Borges, JL (1985) Los conjurados. Obras Completas. Tomo III. Buenos Aires/ Emecé editores/p. 481 